\section{Application of Land Surface Temperature Analysis in Urban Green Spaces: Case Studies from South Asia}

Gl_Forum 2021, Issue 2

Page: 202 - 214

Full Paper

Corresponding Author:

gulam.mohiuddin@hnee.de

DOI: 10.1553/giscience2021_02_s202

\author{
Gulam Mohiuddin and Jan-Peter Mund \\ Eberswalde University for Sustainable Development, Germany
}

\begin{abstract}
This paper demonstrates the use of remote sensing in planning urban green spaces (UGSs). UGSs emerged as a popular solution to combat the effects of Urban Heat Island, especially in tropical cities. UGS projects often need to identify priority implementation areas due to limited funding for UGSs. This study includes two Asian cities, namely Phnom Penh (Cambodia) and Chittagong (Bangladesh). It is not comparative, but it has identified priority administrative areas for future UGSs in both cities. We used Landsat 8 data and the remote sensing technique Land Surface Temperature (LST) analysis using radiance, temperature brightness and emissivity. LST data were then intersected with the administrative boundaries of the study areas. The identification of priority administrative areas for UGS considered both the area coverage and the percentage of coverage in terms of maximum LST within the administrative units' boundaries. The result found 8 and 10 administrative units to be hotspots for UGSs, for Phnom Penh and Chittagong respectively. The proposed method will be useful to both government and non-government organizations alike, especially in tropical countries.
\end{abstract}

\title{
Keywords:
}

Land Surface Temperature (LST), urban green spaces (UGS), remote sensing

\section{Introduction}

In the modern world, urbanization is an inevitable phenomenon. More than half of the global population currently lives in urban areas, with a projection of reaching $68 \%$ by 2050 , an increase that will be seen especially in Asia (UN DESA | United Nations Department of Economic and Social Affairs, 2018). Urbanization influences various environmental factors, and it has noticeable effects on the local weather and regional climate (Souza et al., 2016). Urban areas have to cope with higher temperatures (both land surface and air temperatures) compared to adjacent rural settings due to the phenomenon known as the urban heat island (UHI) (Arya, 2001).

UHIs have multifaceted negative impacts on both the urban environment and residents. The most common effect is that they contribute to producing excessive heat in urban areas. Different economic classes deal differently with this excessive heat. Relatively poor 
neighbourhoods in the urban areas of developing countries often do not have the physical resources (e.g. air conditioning) to cope with extreme heat (Harlan et al., 2007). While the comparatively richer classes can afford to use such resources, this produces more anthropogenic waste heat, contributing to the increase of the UHI effect itself (Oke, 1982).

UHIs also contribute to extreme weather phenomena such as heatwaves (Tan et al., 2010). Heatwaves affect health, making older people, the chronically ill and pregnant women especially more vulnerable (Hiemstra et al., 2017). There is also a positive correlation between UHIs and increased atmospheric pollution in urban areas where there is intense human activity (Sarrat et al., 2006). In large agglomerations, the effects of UHIs are likely to become exacerbated in the near future due to the increase in global warming (Santamouris, 2014).

A popular mitigation technique for the effects of UHIs is to increase evapotranspiration (Hiemstra et al., 2017) through increasing green spaces and water bodies within cities (Heaviside et al., 2017). The concept of urban green spaces (UGSs) has emerged as one of the most prevalent ideas in this regard (Gillet al., 2007). UGSs can be defined as open areas reserved for different types of green space, including areas of vegetation and water features (WHO, 2017); UGSs may be gardens, parks, other recreational venues, bodies of water, and the vegetated areas themselves can be planned or unplanned (Gupta et al., 2012). Increased vegetation in dense built-up areas can reduce the temperature of an urban area by influencing its microclimate (Givoni, 1991), providing thermal comfort to citizens that can contribute to their wellbeing and mental health (ASHRAE, 2004). The increase of UGSs can also be useful to combat air and noise pollution (Dimoudi \& Nikolopoulou, 2003).

There are challenges related to UGSs, especially in developing countries. In many Asian countries, most UGS efforts are grant-based, or existing green spaces are historical, inherited from royal or colonial eras. There are always resource constraints for the maintenance and enlargement of UGSs, not least because public bodies often have limited funding for UGSrelated activities (Tian et al., 2012). Hence the prioritization of areas for investment is of utmost importance (Coutts et al., 2016). Funding in a city is often based on smaller administrative units. Prioritization based on these smaller administrative boundaries can therefore be helpful for decision-makers.

Remote sensing can be a useful tool for prioritization in terms of effectiveness and efficiency. Recording ground-based temperatures at many reference points is both time-consuming and costly, especially when it has to be carried out frequently and over time in order to understand temperature changes. Remote sensing analysis using satellite imagery provides repeatability and synoptic coverage that address these challenges by taking less time and using fewer resources.

Remote sensing uses the land surface temperature (LST) to understand UHIs through analysing spatial patterns (temperature) and identifying hotspots' where UGS could combat these. Here, 'hotspot' refers to an area with comparatively higher LST within a city. LST is the radiative emission of the surface estimated from the top-of-brightness temperature using the infrared spectral channel of a satellite (Copernicus, 2013). In simpler terms, it can be defined as the 'skin temperature' of the ground (Rajeshwari \& Mani, 2014). LST is widely used to understand and monitor UHIs (Keramitsoglou et al., 2011). There are studies in cities across the world investigating UHIs using LST. These locations include Changchun in China (Yang et al., 2020), Cairo in Egypt (El-Hattab et. al., 2018), Noida City in India (Kikon et al., 2016), 
Ulaanbaatar in Mongolia (Gantumur et al., 2019), Erbil in Iraqi Kurdistan (Rasul et al., 2015), Bishan East and Serangoon Central in Singapore (Nichol, 1996), and Melbourne in Australia (Algretawee et al., 2019).

It is essential to distinguish between LST and air temperature: they are different physical phenomena and are measured differently. Air temperature is measured at a height of about 1.2 $\mathrm{m}$ above the ground, and so is different from the land surface temperature. However, using LST to identify hotspots or priority areas in terms of temperature depends on the assumption that higher LST coincides with higher air temperature (Aniello et al., 1995). One study suggests that air temperature and LST patterns can be substituted for each other (Saaroni et al., 2000). This assumption was tested in a later study, which found that compared to air temperature, LST provides higher local variability (Nichol et al., 2009). Moreover, measuring air temperature provides temperature data at a definite point or transect, whereas LST gives a continuous picture of temperature that is more useful for understanding temperature patterns (Saaroni et al., 2000).

Against this backdrop, this study aims to identify priority areas for UGSs according to their administrative boundaries, by the spatial mapping of LST, in two Asian cities.

\section{Study area}

The first empirical example used in this study is in the capital of Cambodia, Phnom Penh, adjacent to the Basăk, Sab and Mekong river system ('Phnom Penh | national capital, Cambodia', 2021). Phnom Penh has an area of about $680 \mathrm{sq} \mathrm{km}$ (https:/ /www.citiesabc.com/city/page/2 2020) and a population of more than 2 million. The population has seen a steep growth rate, increasing by more than 1.5 million in the last 70 years (Phnom Penh Population 2020 (Demographics, Maps, Graphs), 2021). For administrative purposes, Phnom Penh is divided into City Districts (also known as Khans), which are themselves subdivided into Sangkats. Of the total number of 105 Sangkats (Kang et al., 2021), for this study we considered 80 Sangkats within the Phnom Penh Metropolitan Area. Each Sangkat was allocated a number from 1 to 80, randomly, for identification.

The second case study is in a rapidly growing urban centre, Chittagong (official name: Chattogram) in Bangladesh. The city is located on the South-East coast of Bangladesh, sharing a boundary with the Bay of Bengal. The city's Corporation (i.e. total administrative area) is about 161 square $\mathrm{km}$, comprises 41 administrative units (wards), and is home to more than 2 million residents (Palit, 2001); the area is highly susceptible to different forms of pollution (Hossen \& Hoque, 2018). 


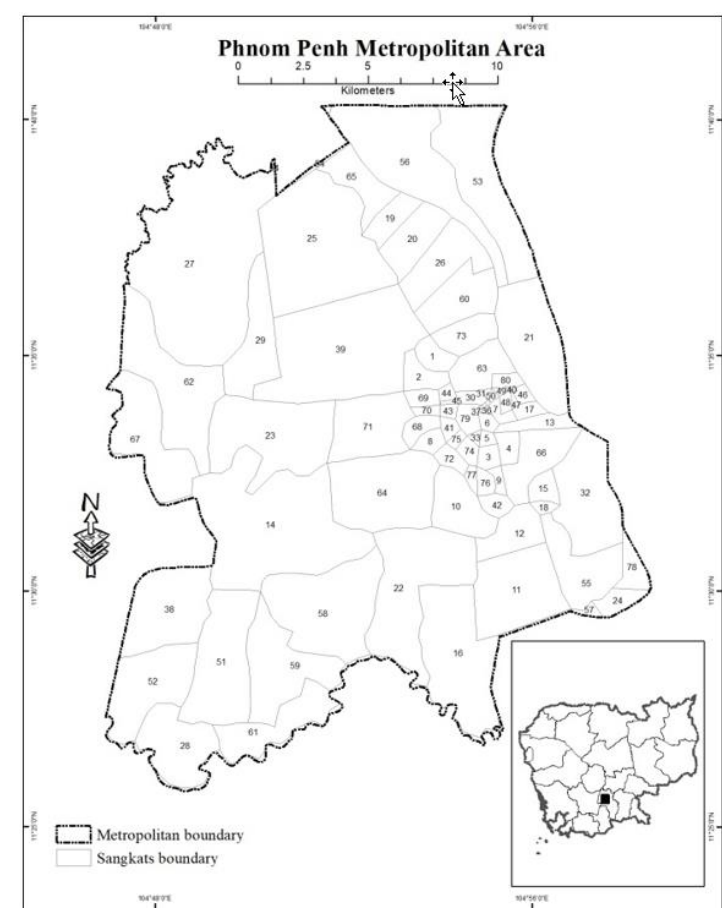

Figure 1: Phnom Penh Metropolitan Area

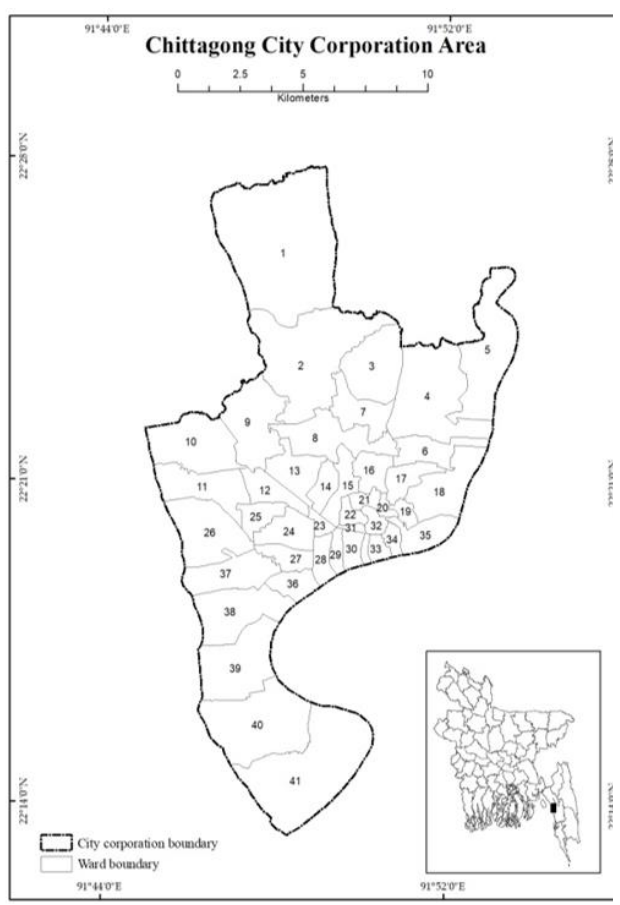

Figure 2: Chittagong City Corporation

\section{Materials and Method}

\subsection{Data and data collection}

The identification of patterns in LST requires coarser spatial resolution (ideally $>30 \mathrm{~m}$ ) to pinpoint the hotspots for UGS (Coutts et al., 2016). Landsat data is suitable for this purpose in local municipalities (Keramitsoglou et al., 2012) because the resolution of Landsat 8's thermal bands is $100 \mathrm{~m}$, which allows LST patterns to be identified, but the data is not too coarse to allow patterns to be extracted at a local scale. The necessary data for this study (Landsat 8 OLI/TIRS C1 Level-1) was downloaded from the USGS website (https://earthexplorer.usgs.gov/) (see Table 1); the areas of interest were defined by the boundaries of the two metropolitan areas. Less than $10 \%$ cloud cover in the image frame was used as the criterion for selecting images. The city boundaries were then carefully checked to ensure they were cloud-free, because cloud cover can affect the LST estimation (Wang et al., 2019). 
Table 1: The data

\begin{tabular}{|l|l|l|}
\hline & Phnom Penh & Chittagong \\
\hline LANDSAT_SCENE_ID & LC81260522020013LGN00 & LC81360452020019LGN00 \\
\hline WRS_PATH & 126 & 136 \\
\hline WRS_ROW & 52 & 45 \\
\hline NADIR_OFFNADIR & NADIR & NADIR \\
\hline DATE_ACQUIRED & $1 / 13 / 2020$ & $1 / 19 / 2020$ \\
\hline SCENE_CENTER_TIME & $03: 20: 12.5437870 Z$ & $04: 19: 11.9031299 Z$ \\
\hline CLOUD_COVER & 10.22 & 3.55 \\
\hline CLOUD_COVER_LAND & 10.22 & 4.85 \\
\hline
\end{tabular}

\subsection{Image processing and estimation of LST}

Various algorithms have been used in different studies to estimate LST (Rajeshwari \& Mani, 2014). In this study, LST was estimated using one thermal infrared (TIR) band (band 10), and three operational land imager (OLI) bands (bands $3,4,5$ ) of Landsat 8 . The equations used in estimating LST were taken from Avdan \& Jovanovska (2016). As per the suggestion from the USGS (6 January 2014) in order to avoid greater calibration uncertainty, TIR band 11 was not included.

Preprocessing of LANDSAT data is required to reduce the solar, atmospheric and topographic effects, including distortion due to the sensor. LANDSAT Level-1 products are geometrically corrected (Young et al., 2017). Conversion to radiance (Equation 1) and thermal calibration (Equation 2) were done as part of preprocessing.

$$
\text { Radiance }=\mathbf{R}=\mathbf{M L} * \mathbf{Q c a l}+\mathrm{AL}
$$

where $\mathrm{ML}$ and $\mathrm{AL}$ are band-specific multiplicative rescaling factors, and Qcal is the thermal band of Landsat 8 (band 10) used in this study.

Top-of-atmosphere brightness temp. $=\mathrm{TB}=(\mathrm{K} 2 / \ln (\mathrm{K} 1 / \mathrm{R}+1)-273.15$

where, ' is the top-of-atmosphere spectral radiance, and K1 and K2 are band-specific thermal conversion constants.

The Normalized Difference Vegetation Index (NDVI) (Equation 3) and proportion of vegetation (Equation 4) were calculated to estimate emissivity (Equation 5).

NDVI $=($ NIR - Red $) /($ NDVI + Red $)$

Prop. of vegetation $=P v=((\text { NDVI }- \text { NDVImin }) /(\text { NDVImax }- \text { NDVImin }))^{\wedge} 2($ eqn 4$)$

Emissivity $=\mathrm{E}=0.004 * \mathrm{Pv}+0.986$

The LST was then estimated using the temperature brightness, radiance, Planck's constant, velocity of light and emissivity: 
$\mathrm{LST}=\mathrm{TB} /[1+(\mathrm{R} * \mathrm{~TB} /(\mathrm{h} * \mathrm{c} / \mathrm{s})) * \ln (\mathrm{e})$

(eqn 6)

where TB is the top-of-atmosphere brightness temperature, $\mathrm{R}$ is the wavelength of the emitted radiance, $\mathrm{h}$ is Planck's constant, $\mathrm{c} / \mathrm{s}$ is the velocity of light per second, and e stands for emissivity.

\subsection{Determining the analysis threshold}

The LST observed in Phnom Penh ranges from $22.96^{\circ} \mathrm{C}$ to $36.64^{\circ} \mathrm{C}$, and for Chittagong from $17.42^{\circ} \mathrm{C}$ to $31.82^{\circ} \mathrm{C}$. The different amplitudes of the LST ranges do not allow any direct physical or climatological comparison of the cities. Hence, the spatial appearance of LST and the priority areas are shown separately, and the temperature categories (Table 2) are subjectively created, based on the temperature range of each city. In both cities, locations in category 5 are considered hotspots because they show the highest LST range for each city individually.

Table 2: LST thresholds of the two cities

\begin{tabular}{|lll|}
\hline Category & \multicolumn{1}{l}{ Phnom Penh } & \multicolumn{1}{l}{ Chittagong } \\
\hline 1 & Up to $25.5^{\circ} \mathrm{C}$ & \multicolumn{1}{l}{ Up to $18.5^{\circ} \mathrm{C}$} \\
\hline 2 & $25.5^{\circ} \mathrm{C}$ to $27.5^{\circ} \mathrm{C}$ & $18.5^{\circ} \mathrm{C}$ to $20.5^{\circ} \mathrm{C}$ \\
\hline 3 & $27.5^{\circ} \mathrm{C}$ to $29.5^{\circ} \mathrm{C}$ & $20.5^{\circ} \mathrm{C}$ to $22.5^{\circ} \mathrm{C}$ \\
\hline 4 & $29.5^{\circ} \mathrm{C}$ to $30.5^{\circ} \mathrm{C}$ & $22.5^{\circ} \mathrm{C}$ to $24.5^{\circ} \mathrm{C}$ \\
\hline 5 & Above $30.5^{\circ} \mathrm{C}$ & Above $24.5^{\circ} \mathrm{C}$ \\
\hline
\end{tabular}

\subsection{Criteria for selecting priority administrative areas}

Category 5 LST locations (hotspots) were intersected with the administrative boundaries to identify priority administrative units (i.e. Sangkats and wards). Two criteria were considered in order to identify priority units:

1: What is the area of an administrative unit covered by hotspots? The top five administrative units in terms of area covered by hotspots are considered priority units.

2: What percentage of a particular administrative unit is covered by hotspots? The top five administrative units in terms of percentage coverage are selected as priority units.

\section{Results}

In Phnom Penh, the highest LST areas on 13 January 2020 were observed predominantly in the western part of the city (Figure 3). Specifically, there is a concentration of hotspots (category 5 LST) in the southwest of the city. The water bodies in the eastern and northern parts show lower LST. 


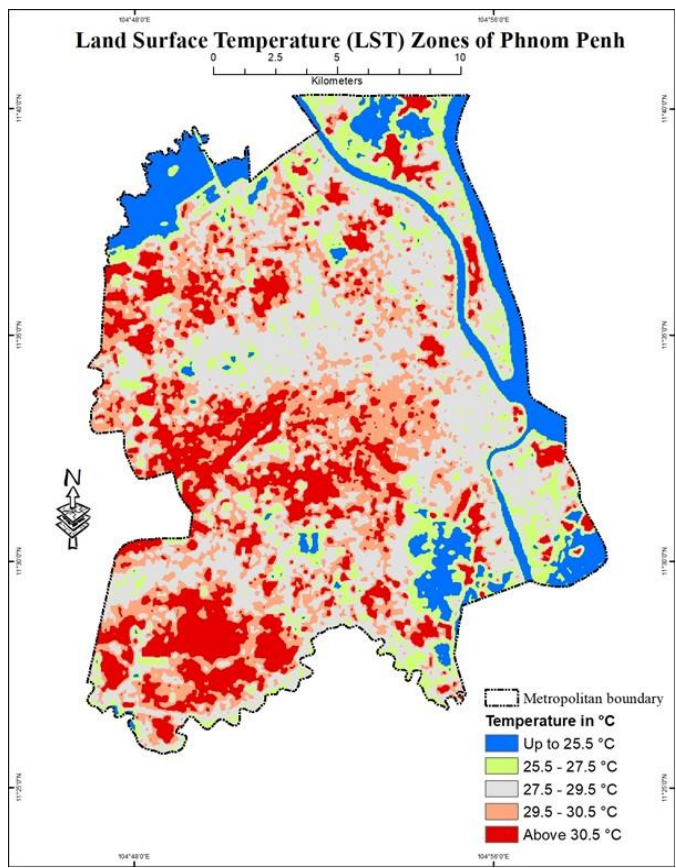

Figure 3: LST distribution of Phnom Penh

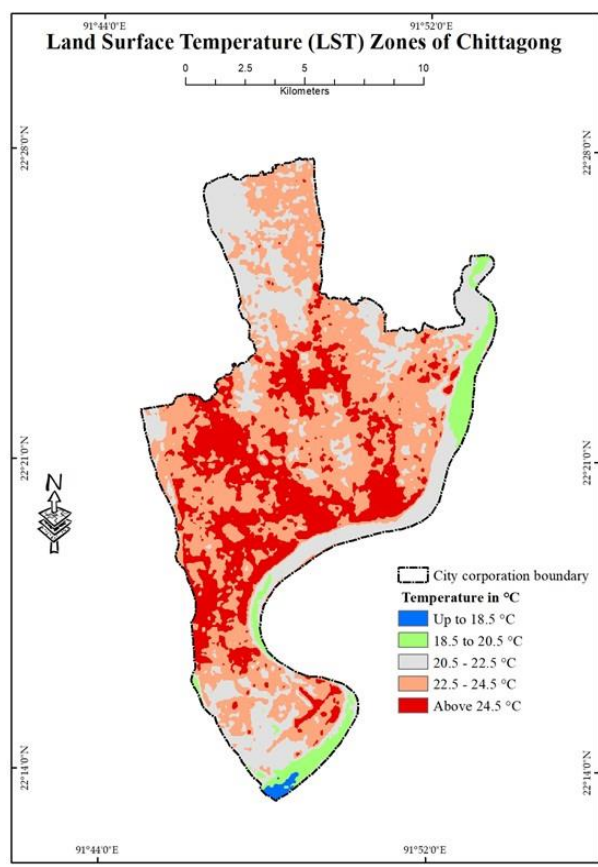

Figure 4: LST of Chittagong

For Chittagong (19 January 2020), most hotspots were scattered in the central area of the city, and lower LST was found within or close to open water bodies (Figure 4).

Figures 5-8 illustrate which administrative units fulfil the criteria for selection as priority areas.

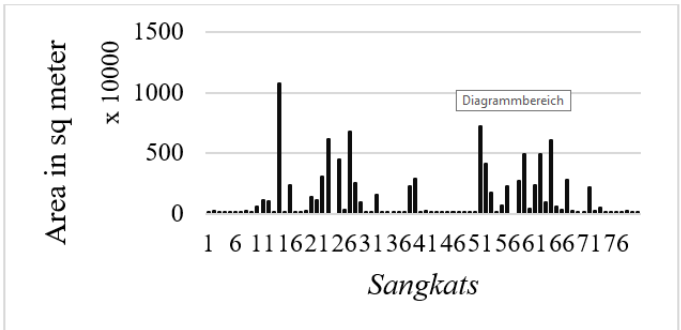

Figure 5: Area coverage of the hotspots (Phnom Penh)

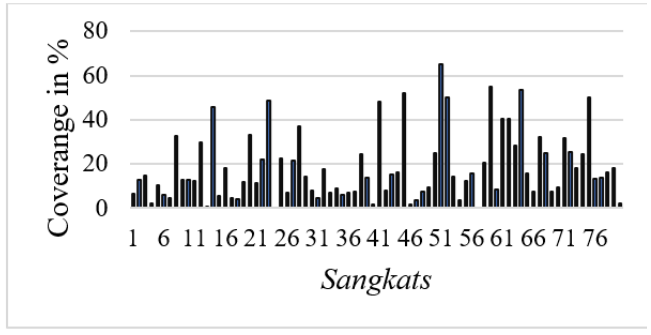

Figure 6: Percentage of coverage of hotspots (Phnom Penh) 


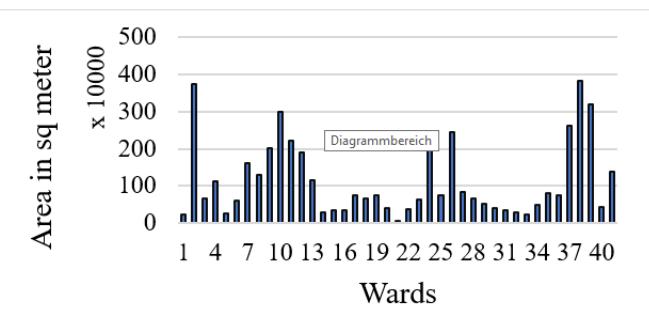

Figure 7: Area coverage of hotspots (Chittagong)

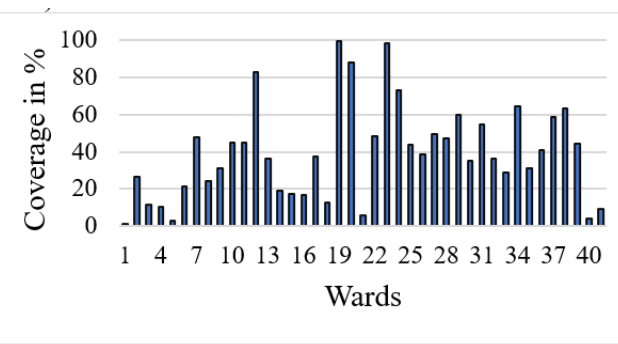

Figure 8: Percentage of coverage of hotspots (Chittagong)

The top five administrative units for both criteria and for each city (i.e. a total of 10 for each city) are presented in Tables 3 and 4. In Phnom Penh, two Sangkats (Pong Tuek and Stueng Mean Chey) figure among the top 5 for both criteria; for Chittagong, there is no such overlapping between the wards. Hence, eight Sangkats from Phnom Penh and ten wards from Chittagong were selected as priority administrative units for urban green spaces (Figures 11 and 12).

Table 3: Top five administrative units in terms of area coverage

\begin{tabular}{l|llll}
\hline \multicolumn{4}{l}{ Area covered by the highest LST zone } \\
\hline Rank & Phnom Penh & & Chittagong & \\
& Sangkat & Coverage (Area in sq m) & Ward no. & Coverage (Area in sq m) \\
1 & Chaom & $10,749,123$ & 38 & $3,820,428$ \\
& Chau & & & \\
2 & Pong Tuek & $7,210,586$ & 2 & $3,743,287$ \\
3 & Kouk Roka & $6,812,670$ & 39 & $3,187,357$ \\
4 & Kakab & $6,164,877$ & 10 & $3,001,345$ \\
5 & Stueng & $6,065,042$ & 37 & $2,610,842$ \\
\end{tabular}

Table 4: Top five administrative units in terms of coverage percentage

\begin{tabular}{l|llll}
\hline \multicolumn{3}{l}{ Percentage of unit coverage in the highest LST zone } \\
\hline Rank & Phnom Penh & Chittagong \\
& Sangkat & Covarage (\%) & Ward no & Coverage (\%) \\
1 & Pong Tuek & 65.15 & 19 & 99.86 \\
2 & Prey Veaeng & 55.04 & 23 & 98.34 \\
3 & Stueng Mean Chey & 53.72 & 20 & 88.40 \\
4 & Phsar Depou Ti Pir & 52.10 & 12 & 82.92 \\
5 & Tuol Svay Prey Ti Pir & 50.08 & 24 & 72.94 \\
\hline
\end{tabular}




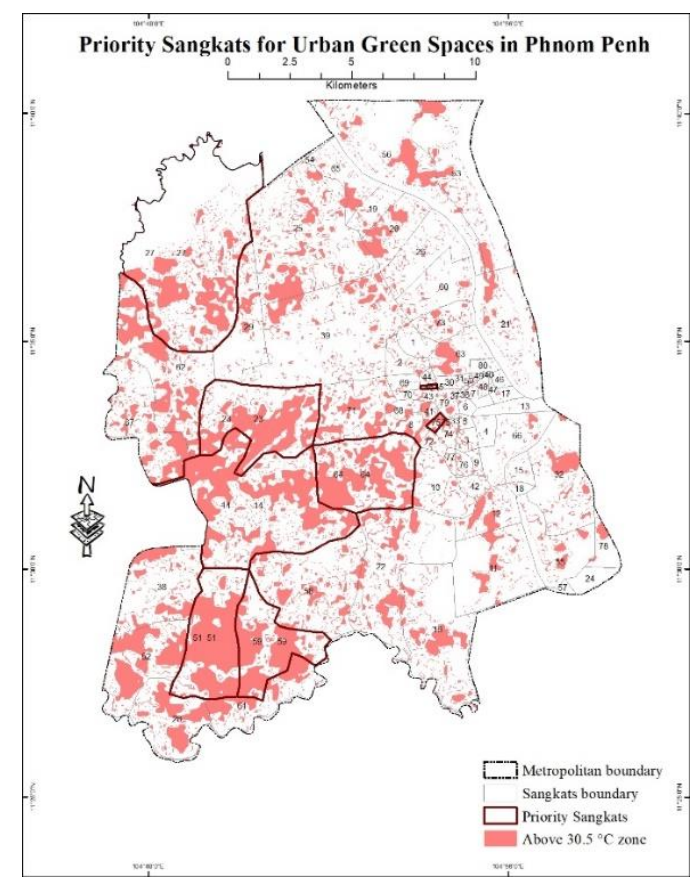

Figure 9: Priority areas of Phnom Penh

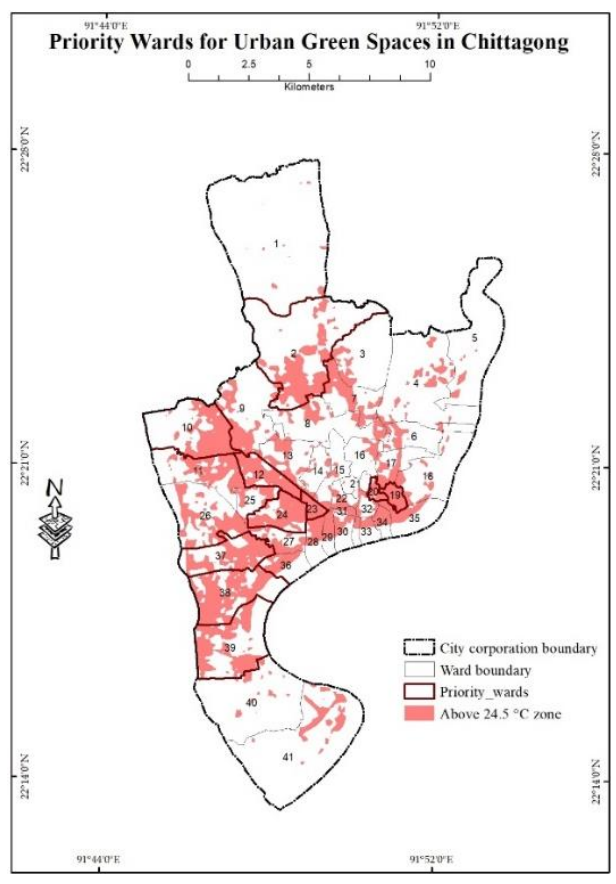

Figure 10: Priority areas of Chittagong

\section{Discussion}

This study has shown the LST distribution in two Asian cities in January 2020, the dry season in both areas. But it is important to remember that UHIs can vary significantly, over space and time (Grimmond et. al., 1993). Hence, the temperature ranges the study provided cannot be generalized over the year or to other cities.

The study identified the priority administrative units for urban green spaces, but it does not specify what types of UGS should be prioritized (parks, water bodies etc.). One study suggests that trees are more efficient and beneficial from an ecological point of view (Hiemstra et al., 2017), but this needs to be investigated further through studies comparing different types of UGS. In addition, social factors need to be taken into account in deciding the type of UGS to be established. For example, a park is appreciated differently by elderly and by young people (Gupta et. al., 2012).

The approach presented here of understanding the LST patterns in an urban area is a good substitute for recording ground-based temperature, considering resources, time, effort and repeatability (for change analysis). Presenting the results based on administrative units makes the method more user-friendly for urban decision-makers, who often need ready and accessible products to help them (Coutts et al., 2016).

The study identified eight Sangkats and ten wards as priority areas for Phnom Penh and Chittagong respectively. The overlap that happened in Phnom Penh cannot be explained 
without further investigation, but it indicates that these two Sangkats require more attention in terms of UGS. However, LST should not be the only consideration in prioritizing areas for UGS. There are other important factors, such as the density of built-up areas, building heights and types (Schöpfer et al., 2005), existing vegetation and open spaces, that need to be considered in the planning and implementation of UGS.

The LST estimation for this study was done using existing images, so a real-time ground validation of LST was not possible. However, because the study's objective was to identify hotspots based on the highest LST (regardless of the absolute temperature ranges), the analysis is still valid for identifying the comparatively higher LST areas. For the same reason, seasonal variation was not considered. Future studies that use absolute air $(1.2 \mathrm{~m})$ and surface temperature for analysis would need to conduct ground validation.

The study has shown the distribution of LST in two cities at a particular time, but it does not explain the change scenario or the causes behind the distribution that was found. Further research is required to understand the different distributions of LST within the cities. It would also be useful, in order to understand the cause of change and distribution patterns, to triangulate LST and land-use change using very high resolution (VHR) TIR data (Kottmeier et al., 2007).

\section{Conclusion}

While estimating LST can be useful for UGSs, it does not lessen the importance of the urban climate model using air temperature. The approaches can complement each other and encourage collaboration between spatial planners and climate scientists. Although an increase of UGS can help combat the negative effects of UHIs, more than one type of action is required to combat them efficiently. Using reflective or 'cool' building materials and surfaces is another helpful approach. In addition, changing people's behaviour, so that less anthropogenic heat is emitted, could also make a significant contribution (Heaviside et al., 2017).

The present study will be particularly useful for urban planners, city authorities and organizations involved with UGS. However, the use of LST is not limited to the planning phase. It can also be an effective and efficient way to monitor and evaluate UGSs. LST can be a key indicator of negative UHI effects and a key consideration in UGS-related efforts.

It is important to understand the different spatial patterns that exist in urban areas. UGSs can act as a network that will help transform a city's green infrastructure more broadly. This transformation towards a green infrastructure is needed to combat UHIs and atmospheric pollution, while also contributing to an urban population's quality of life by helping with both physical and mental health. 


\section{References}

Algretawee, H., Rayburg, S., \& Neave, M. (2019). Estimating the effect of park proximity to the central of Melbourne city on Urban Heat Island (UHI) relative to Land Surface Temperature (LST). Ecological Engineering, 138, 374-390.

Aniello, C., Morgan, K., Busbey, A., Newland, L. (1995). Mapping Micro-Urban Heat Islands Using Landsat TM and a GIS. Computers \& Geosciences, 21, 965-969.

Arya, S. P. (2001). Introduction to micrometeorology (2nd ed.). This is volume 79 in the International geophysics series. San Diego: Academic Press.

ASHRAE (2004). Thermal Environmental Conditions for Human Occupancy. (55), 2-25.

Avdan, U., \& Jovanovska, G. (2016). Algorithm for Automated Mapping of Land Surface

Temperature Using LANDSAT 8 Satellite Data. Journal of Sensors, 2016, 1-8.

https://doi.org/10.1155/2016/1480307

Copernicus. (2013). Land Surface Temperature. Retrieved 11 July 2021, from https://land.copernicus.eu/global/products/lst

Coutts, A. M., Harris, R. J., Phan, T., Livesley, S. J., Williams, N. S.G., \& Tapper, N. J. (2016). Thermal infrared remote sensing of urban heat: Hotspots, vegetation, and an assessment of techniques for use in urban planning. Remote Sensing of Environment, 186, 637-651. https://doi.org/10.1016/j.rse.2016.09.007

Dimoudi, A., Nikolopoulou, M. (2003). Vegetation in the urban environment: microclimatic analysis and benefits. Energy and Buildings, 35, 69-76.

El-Hattab, M., Amany, S. M., \& Lamia, G. E. (2018). Monitoring and assessment of urban heat islands over the Southern region of Cairo Governorate, Egypt. The Egyptian Journal of Remote Sensing and Space Science, 21(3), 311-323.

Gantumur, B., Wu, F., Vandansambuu, B., Dalaibaatar, E., Tumursukh, B., Munkhsukh, U., \& Zhao, Y. (2019, October). Implication of urban heat island (UHI) related to human activities: a case study in Mongolia. In Remote Sensing Technologies and Applications in Urban Environments IV (Vol. 11157, p. 111570V). International Society for Optics and Photonics.

Gill, S.E., Handley, J.F., Ennos, A.R., \& Pauleit, S. (2007). Adapting Cities for Climate Change: The Role of the Green Infrastructure. Built Environment, 33(1), 115-133. https://doi.org/10.2148/benv.33.1.115

Grimmond, Christine \& Oke, T. \& Cleugh, Helen (1993). The role of 'rural' in comparison of observed suburban-rural flux differences. Proceedings of the Yokohama Symposium, 212, 165 174.

Gupta, K., Kumar, P., Pathan, S. K., \& Sharma, K. P. (2012). Urban Neighborhood Green Index - A measure of green spaces in urban areas. Landscape and Urban Planning, 105(3), 325-335. https://doi.org/10.1016/j.landurbplan.2012.01.003

Givoni, B. (1991). Impact of planted areas on urban environmental quality: A review. Atmospheric Environment, 25B(3), 289-299.

Harlan, S. L., Brazel, A. J., Jenerette, G. D., Jones, N. S., Larsen, L., Prashad, L., \& Stefanov, W. L. (2007). In the shade of affluence: the inequitable distribution of the urban heat island. In Research in Social Problems and Public Policy. Equity and the Environment (Vol. 15, pp. 173-202). Bingley: Emerald (MCB UP ). https://doi.org/10.1016/S0196-1152(07)15005-5

Heaviside, C., Macintyre, H., \& Vardoulakis, S. (2017). The Urban Heat Island: Implications for Health in a Changing Environment. Current Environmental Health Reports, 4(3), 296-305. https://doi.org/10.1007/s40572-017-0150-3

Hiemstra, J. A., Saaroni, H., \& Amorim, J. H. (2017). The Urban Heat Island: Thermal Comfort and the Role of Urban Greening. In D. Pearlmutter, C. Calfapietra, R. Samson, L. O'Brien, S. Krajter Ostoić, G. Sanesi, \& R. Alonso del Amo (Eds.), Future City. The Urban Forest (Vol. 7, pp. 7-19). Cham: Springer International Publishing. https://doi.org/10.1007/978-3-319-50280-9_2 
Hossen, M. A., Hoque, A. (2018). Variation of Ambient air Quality Scenario in Chittagong City: A Case Study of Air Pollution. Journal of Civil, Construction and Environmental Engineering, 3(1), 10. https://doi.org/10.11648/j.jccee.20180301.13

Kang, B., Bei, B., m, บ., Muoy, B., ๑, U., \& Pir, B. et al. (2021). Cambodia: Phnom Penh (City Districts and Communes) - Population Statistics, Charts and Map. Retrieved 27 June 2021, from https://www.citypopulation.de/en/cambodia/phnompenh/admin/

Keramitsoglou, I., Daglis, I. A., Amiridis, V., Chrysoulakis, N., Ceriola, G., Manunta, P, Paganini, M. (2012). Evaluation of satellite-derived products for the characterization of the urban thermal environment. Journal of Applied Remote Sensing, 6(1), 61704. https://doi.org/10.1117/1.JRS.6.061704

Keramitsoglou, I., Kiranoudis, C. T., Ceriola, G., Weng, Q., \& Rajasekar, U. (2011). Identification and analysis of urban surface temperature patterns in Greater Athens, Greece, using MODIS imagery. Remote Sensing of Environment, 115(12), 3080-3090.

Kikon, N., Singh, P., Singh, S. K., \& Vyas, A. (2016). Assessment of urban heat islands (UHI) of Noida City, India using multi-temporal satellite data. Sustainable Cities and Society, 22, 19-28.

Kottmeier, C, Biegert, Corsmeier, a., \& U (2007). Effects of Urban Land Use on Surface Temperature in Berlin: Case Study. Journal of Urban Planning and Development, 133(2).

Nichol, J. E. (1996). High-resolution surface temperature patterns related to urban morphology in a tropical city: a satellite-based study. Journal of Applied Meteorology and Climatology, 35(1), 135 146.

Nichol, J. E., Fung, W. Y., Lam, K.-s., \& Wong, M. S. (2009). Urban heat island diagnosis using ASTER satellite images and 'in situ' air temperature. Atmospheric Research, 94(2), 276-284. https://doi.org/10.1016/j.atmosres.2009.06.011

Oke, T.R (1982). The energetic basis of the urban heat island. Quarterly Journal of the Royal Meteorological Society, 108, 1-24. https://doi.org/10.1002/qj.49710845502

Palit, T. (2001). Chittagong City Corporation. In National Encyclopedia of Bangladesh. Dhaka: Government of People's Republic of Bangladesh.

Phnom Penh Population 2020 (Demographics, Maps, Graphs). (2021). Retrieved 27 June 2021, from https://worldpopulationreview.com/world-cities/phnom-penh-population

Phnom Penh | national capital, Cambodia. (2021). Retrieved 27 June 2021, from https://www.britannica.com/place/Phnom-Penh Gao, B. (1996). NDWI-A normalized difference water index for remote sensing of vegetation liquid water from space. Remote Sensing of Environment, 58(3), 257-266. doi: 10.1016/s0034-4257(96)00067-3

Rajeshwari A, Mani N. D. (2014). Estimation of Land Surface Temperature of Dindigul District using Landsat 8 Data. IJRET: International Journal of Research in Engineering and Technology, 3(5), 122-126.

Rasul, A., Balzter, H., \& Smith, C. (2015). Spatial variation of the daytime Surface Urban Cool Island during the dry season in Erbil, Iraqi Kurdistan, from Landsat 8. Urban climate, 14, 176-186.

Saaroni, H., Ben-Dor, E., Bitan, A., Potchter, O. (2000). Spatial distribution and microscale characteristics of the urban heat island in Tel-Aviv, Israel. Landscape and Urban Planning, 48, $1-$ 18.

Santamouris, M. (2014). On the energy impact of urban heat island and global warming on buildings. Energy and Buildings, 82, 100-113. https://doi.org/10.1016/j.enbuild.2014.07.022

Sarrat, C., Lemonsu, A., Masson, V., \& Guedalia, D. (2006). Impact of urban heat island on regional atmospheric pollution. Atmospheric Environment, 40(10), 1743-1758. https://doi.org/10.1016/j.atmosenv.2005.11.037

Souza, D. O. de, Alvalá, R. C. d. S., \& Nascimento, M. G. d. (2016). Urbanization effects on the microclimate of Manaus: A modeling study. Atmospheric Research, 167, 237-248. https://doi.org/10.1016/j.atmosres.2015.08.016 
Schöpfer, E., Lang, S., Blaschke, T. (2005). A “Green Index” Incorporating Remote Sensing and Citizen's Perception of Green Space.

Tan, J., Zheng, Y., Tang, X., Guo, C., Li, L., Song, G., . . Li, F. (2010). The urban heat island and its impact on heat waves and human health in Shanghai. International Journal of Biometeorology, 54(1), 75-84. https://doi.org/10.1007/s00484-009-0256-x

Tian, Y., Jim, C. Y., \& Tao, Y. (2012). Challenges and Strategies for Greening the Compact City of Hong Kong. Journal of Urban Planning and Development, 138(2), 101-109. https://doi.org/10.1061/(ASCE)UP.1943-5444.0000076

UN DESA. (2018). $68 \%$ of the world population projected to live in urban areas by 2050 , says UN | UN DESA | United Nations Department of Economic and Social Affairs. Retrieved 11 February 2021, from https://www.un.org/development/desa/en/news/population/2018-revision-ofworld-urbanization-prospects.html

WHO. (2017). Urban green spaces: a brief for action (p. 2). Copenhagen: World Health Organization, Regional Office for Europe. Retrieved from https://www.euro.who.int/_data/assets/pdf_file/0010/342289/Urban-GreenSpaces_EN_WHO_web3.pdf

Wang, T., Shi, J., Ma, Y., Husi, L., Comyn-Platt, E., Ji, D., . . Xiong, C. (2019). Recovering Land Surface Temperature Under Cloudy Skies Considering the Solar-Cloud-Satellite Geometry: Application to MODIS and Landsat-8 Data. Journal of Geophysical Research: Atmospheres, 124(6), 3401-3416. https:/ / doi.org/10.1029/2018JD028976

Yang, C., Yan, F., \& Zhang, S. (2020). Comparison of land surface and air temperatures for quantifying summer and winter urban heat island in a snow climate city. Journal of environmental management, 265, 110563

Young, N. E., Anderson, R. S., Chignell, S. M., Vorster, A. G., Lawrence R., Evangelista, P. H. (2017). A survival guide to Landsat preprocessing. Ecology, 98(4), 920-932. 